\title{
铑催化不对称碳氢键活化合成平面手性二茂铁化合物
}

\author{
段伟良 $* a, b$ \\ ( ${ }^{a}$ 扬州大学化学化工学院 江苏扬州 225002) \\ $\left({ }^{b}\right.$ 陕西师范大学化学化工学院 西安 710119)
}

\section{Rh-Catalyzed Asymmetric C-H Activation for the Synthesis of Planar Chiral Ferrocenes}

\author{
Duan, Wei-Liang ${ }^{* a, b}$ \\ ( ${ }^{a}$ College of Chemistry and Chemical Engineering, Yangzhou University, Yangzhou, Jiangsu 225002) \\ ( ${ }^{b}$ School of Chemistry and Chemical Engineering, Shaanxi Normal University, Xi'an 710119)
}

碳氢键官能团化反应是有机合成领域广受关注的 反应之一. 这一过程可以通过直接切断反应物的碳氢键 来构建各种碳碳、碳杂原子键, 生成多种类型的化合物. 相对于必须使用含官能团的化合物为原料的合成过程, 碳氢键官能团化反应有潜在、相对更适应可持续发展绿 色化学的要求. 过去二十年来, 导向基团辅助的碳氢键 活化反应有着十分快速的发展, 各种过渡金属如钯、铑、 钉、铱、铜、钴、镍、锰等被广泛应用于碳氢键官能团 化反应之中 ${ }^{[1]}$. 然而催化不对称碳氢活化反应的研究还 远远滞后, 目前应用范围相对较广的催化体系为钯/单 保护氨基酸、钯/手性膦配体和手性环戌二烯铑的催化 剂 ${ }^{[2,3]}$. 相对于不对称氢化、不对称偶联、不对称烯丙基 取代等反应可使用的多种高效手性催化剂而言, 适用于 碳氢活化反应的有效手性配体及催化剂的类型和应用 范围还远远不够, 这一领域急需进一步探索发展.

平面手性化合物具有鲜明结构特点, 被广泛应用于 催化反应中作为配体及催化剂(图 1) ${ }^{[4 \sim 6]}$. 这类化合物的 合成也受到研究者的长期关注. 早期的合成路线多为直 接使用手性辅基或光学纯化合物作为原料来构建目标 分子. 不对称催化的方法后期也被应用于平面手性化合 物的合成之中. 值得指出的是, 不对称碳氢键活化近来 也被研究者应用于合成平面手性化合物, 取得了突破性 的进展, 但在导向基团的种类、反应类型的多样化等方 面仍有待拓展深入研究 ${ }^{[7]}$.

最近中国科学院上海有机化学研究所游书力课题 组利用一价铑催化剂/手性膦配体 ${ }^{[8,9]}$, 实现了硫代酮导 向的二茂铁类化合物的分子间不对称芳基化反应, 产物

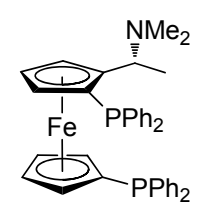

BPPFA

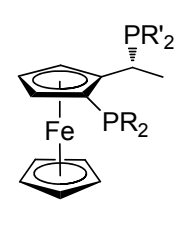

Josiphos

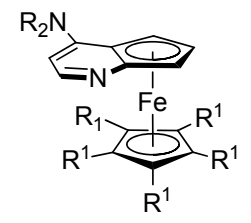

Fu's chiral DMAP
图 1 代表性的平面二茂铁手性配体

Figure 1 Representative planar-chiral ferrocene-based ligands 的立体选择性最高可达 $99 \%{ }^{[10]}$.

研究初期, 他们尝试了使用钯催化剂, 利用不对称 碳氢活化反应中常用的单保护氨基酸配体以及手性磷 酸添加剂, 但结果都不理想, 反应的立体选择没有得到 控制，只得到消旋产物(图 2) ${ }^{[10]}$. 他们后期发现一价铑 催化剂结合手性膦配体可以实现对产物立体选择性的 控制. 在优化反应条件之后, 最终使用酒石酸衍生的三 价膦配体取得了优异的立体选择性和良好的收率(图 3).

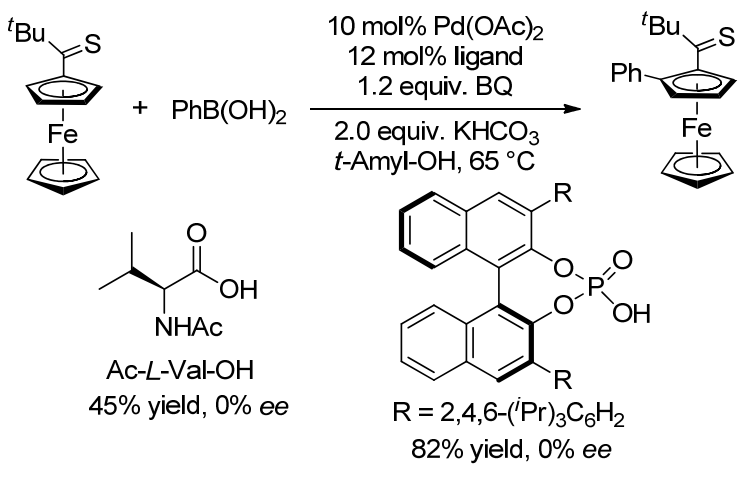

图 2 使用钯催化剂手性酸配体的实验结果

Figure 2 Experimental results with Pd catalyst and chiral acids

* Corresponding author. E-mail: duanwl@yzu.edu.cn. published online November 21, 2019. 

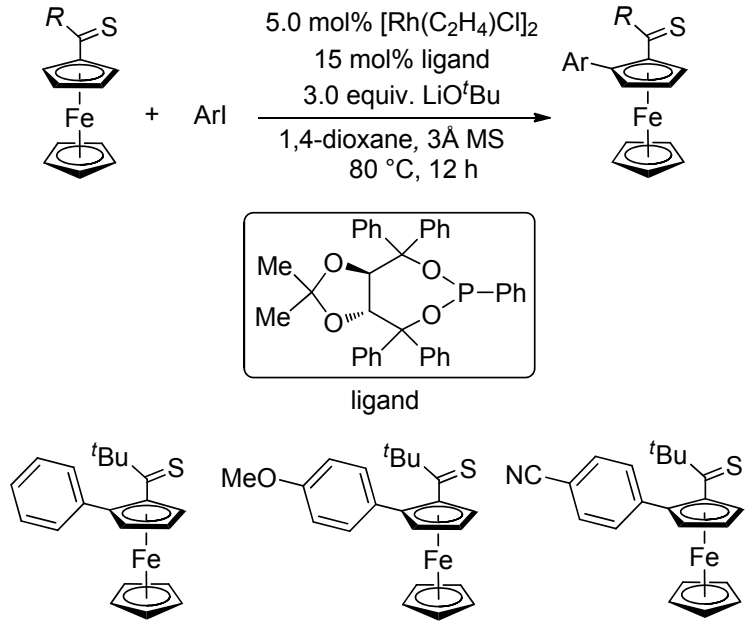

$76 \%$ yield, $97 \%$ ee

$78 \%$ yield, $95 \%$ ee

$72 \%$ yield, $89 \%$ ee
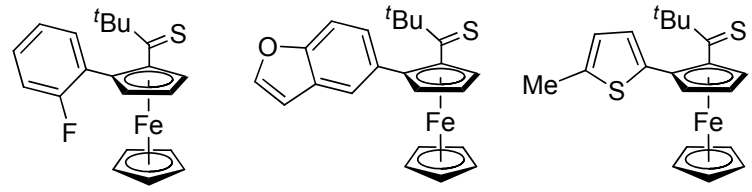

$76 \%$ yield, $94 \%$ ee

$74 \%$ yield, $91 \%$ ee

$63 \%$ yield, $90 \%$ ee

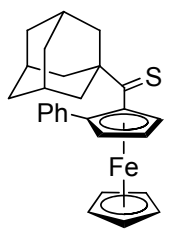

$65 \%$ yield, $>99 \%$ ee

$72 \%$ yield, $89 \%$ ee

图 3 铑催化不对称碳氢活化合成平面手性二茂铁

Figure 3 Rh-catalyzed asymmetric $\mathrm{C}-\mathrm{H}$ arylation for the synthesis of planar chiral ferrocene compounds
这一反应条件温和, 底物范围广, 可以容忍多种供电子 及吸电子取代基, 杂环碘代物如苯并呋喃、噻吩、吡啶 等也可被用于这一催化反应之中，获得包含各种杂环结 构单元的平面手性二茂铁化合物. 对比和机理实验表 明，相对于酮羰基而言，使用具有更强的配位能力的硫 代酮, 是反应进行的必要条件之一. 二茂铁环上碳氢键 的切断是可逆的, 不涉及反应的决速步骤之中.

总之, 游书力课题组发展了使用一价铑催化剂结合 手性膦配体，高效构建平面手性二茂铁化合物的新方 法. 这一发现有助于吸引研究者去尝试探索各种新的可 适用于不对称碳氢键官能团化反应的催化体系, 进一步 促进碳氢活化反应在手性化合物的合成构建方向上的 发展.

\section{References}

[1] Eds.: Yu, J.-Q.; Shi, Z. C-H Activation. Topics in Current Chemistry, Vol. 292, Springer, Berlin, 2010.

[2] Zheng, C.; You, S.-L. RSC Adv. 2014, 4, 6173.

[3] Newton, C. G.; Wang, S.-G.; Oliveira, C. C.; Cramer, N. Chem. Rev. 2017, 117, 8908 .

[4] Hayashi, T.; Kumada, M. Acc. Chem. Res. 1982, 15, 395.

[5] Togni, A. Chimia 1996, 50, 86.

[6] Fu, G. C. Acc. Chem. Res. 2000, 33, 412.

[7] Gao, D.-W.; Gu, Q.; Zheng, C.; You, S.-L. Acc. Chem. Res. 2017, $50,351$.

[8] Kim, J.-H.; Greßies, S.; Boultadakis-Arapinis, M.; Daniliuc, C.; Glorius, F. ACS Catal. 2016, 6, 7652.

[9] Greßies, S.; Klauck, F. J. R.; Kim, J. H.; Daniliuc, C. G.; Glorius, F. Angew. Chem., Int. Ed. 2018, 57, 9950.

[10] Cai, Z.-J.; Liu, C.-X.; Wang, Q.; Gu, Q.; You, S.-L. Nat. Commun. 2019, 10, 4168.

(Cheng, F.) 